\title{
NATUREZA ÉTICO-POLÍTICA DAS DIMENSÕES HUMANAS DAS MUDANÇAS AMBIENTAIS GLOBAIS
}

\author{
Roberto Pereira Guimarães \\ Prof. Fundação Getúlio Vargas \\ robertoguimaraes@hotmail.com
}

Yuna Souza dos Reis da Fontoura

Yuna.Fontoura@fgv.br

Resumo

A globalização da crise ambiental impõe o reconhecimento de que a história do Ser Humano é, na verdade, a história de suas relações com a Natureza. Justifica-se, pois, revisitar as dimensões humanas das mudanças ambientais globais, com ênfase especial nos novos desafios político-institucionais que a crise financeira desta primeira década do século XXI antepõe à agenda internacional.

Palavras-chave: Ttransição ecológica, mudanças ambientais globais, desenvolvimento sustentável, crise financeira, globalização.

\begin{abstract}
The globalization of the environmental crisis imposes the recognition that the history of human beings is, in fact, the history of their relationship with nature. It is important, therefore, to revisit the human dimensions of global environmental change, with special emphasis in the new political and institutional challenges that the financial crisis of this first decade of the XXI century imposes to the international agenda
\end{abstract}

Key Words: Ecological transition, global environmental changes, sustainable development, financial crisis, globalization.

\section{INTRODUÇÃO}

$\mathrm{O}$ ambiente é origem e destino de tudo que caracteriza e nos permite ser humanos. De fato, é do ambiente natural que incorporamos todas as matérias, produtos e serviços ambientais que não apenas permitem o desenvolvimento das atividades necessárias para o bem-estar material, estético e espiritual do ser humano, mas também são indispensáveis para a manutenção da vida no Planeta. É neste mesmo ambiente que armazenamos os subprodutos, rejeitos e excessos de nossas atividades.

Não obstante esta conjuntura, durante muito tempo as mudanças ocorridas no planeta obedeciam muito mais aos vetores, ritmo e características dos ciclos naturais. No entanto, a partir da Revolução Industrial esta realidade mudou dramaticamente. Já não se discute no meio científico se as mudanças globais que dispararam os níveis de alarme em todo o planeta respondem agora, em maior grau, às atividades humanas.

Em outras palavras, a história das relações entre seres humanos e natureza indica que o ser humano foi tornando-se, gradual e inexoravelmente, independente da base natural de recursos como fator determinante do seu bem-estar, graças à incorporação de ambientes apartados por meio do comércio, conquista ou ocupação. Esta faceta, inicialmente benéfica para a evolução da humanidade - sem ela não haveria sido possível a civilização tal como a conhecemos - terminou minando as fundações eco-políticas (i.e., político-institucionais) da civilização ocidental. Na verdade, as mudanças ambientais globais do mundo moderno, que provocam agora uma crise de desenvolvimento sem precedentes na história da humanidade, vem sendo construídas há muitos anos. De fato, elas tiveram início há mais de 9.000 anos, com a domesticação de animais e plantas, dando lugar ao que John Bennet (1976) caracterizou com especial propriedade de Transição Ecológica. 
A Transição Ecológica envolve em termos tecnológicos a tendência a utilizar quantidades cada vez maiores de energia, com níveis cada vez mais elevados de entropia. A tal ponto que, hoje, a cada novo incremento tecnológico, se usa mais energia do que em etapas anteriores, e isto para atender necessidades ecológicas do ser humano que não se modificaram em suas dimensões básicas desde períodos históricos anteriores à Revolução Agrícola. Ecologicamente, ela se caracteriza pela incorporação da natureza na cultura, assim como pelo rompimento das relações de subsistência local com o ambiente, o que significa não apenas a acumulação de bens para fins a cada dia menos relacionados com a sobrevivência, mas a possibilidade de alcançar suficiência ecológica por meio da incorporação de ambientes naturais cada vez mais apartados da comunidade local. Sociologicamente, a transição representa o incremento e a maior complexidade da organização social e das redes de comunicação existentes para dar sustento à expansão da ocupação humana do planeta. Em suas dimensões filosóficas, esta pressupõe a substituição de "imagens" como a de contemplação, respeito e até mesmo de veneração quase religiosa da natureza, pela simples instrumentalização e materialização do mundo natural. Finalmente, a transição se manifesta também politicamente, na medida em que, para alcançar um dado nível de consumo, e portanto, de produção, as sociedades são obrigadas a fazer uso cada vez mais intenso de recursos de poder para ajustarem os requerimentos de tecnologia e de organização social, e uma vez alcançado um novo patamar de desenvolvimento, tornam-se necessários novos ajustes de poder.

Convém reiterar as características mais relevantes da transição para captar as raízes mais remotas da crise atual. Em primeiro lugar, a eclosão da Revolução Agrícola, ao definir as bases para o que poderia ser considerado o primeiro "ordenamento territorial" da história, permitiu que a população passasse a depender cada vez menos do seu entorno imediato para sobrevivência. Isto possibilitou o surgimento de padrões de ocupação do território que favoreciam e se beneficiavam das "economias de escala" produzidas pela aglomeração humana, primeiro em assentamentos, logo em vilas e cidades, até chegar às metrópoles e megalópoles de hoje, um claro indício do esgotamento da "Transição Ecológica". O mesmo padrão de incorporação da natureza que deu lugar ao assentamento mais permanente do ser humano, aumentando consideravelmente o seu bem-estar, atinge agora o limite das metrópoles insustentáveis do ponto de vista energético, ecológico, ambiental e social. Por outro lado, graças à produção e acumulação de excedentes - uma impossibilidade e até mesmo inutilidade antes da Revolução Agrícola - foi possível à população adotar padrões de consumo crescentemente divorciados de suas necessidades biológicas, de sobrevivência.

Finalmente, como resultado das duas dinâmicas precedentes, foi possível, ao conjunto da sociedade, tornar-se progressivamente independente do ambiente natural imediato, possibilitando expandir e consolidar novos padrões de consumo. Embora fossem, a cada nova etapa, mais insustentáveis do ponto de vista ecológico e ambiental, podiam garantir a sua sustentabilidade no curto e médio prazo, graças à incorporação de "novos" ambientes por meio da guerra, do comércio e da tecnologia. Outro claro indício do fim da Transição é o fato de não mais existirem suficientes territórios "virgens" para sustentar a expansão da população nas bases vigentes até aqui, ao mesmo tempo que, a cada nova expansão, a modificação do ambiente é feita com custos tecnológicos, energéticos, ecológicos e ambientais, que superam os benefícios para a sociedade, e os limites quase físicos se fazem mais presentes.

Como se já não fosse suficiente o resultado dos processos analisados anteriormente, centrados exclusivamente nas consequências no longo prazo da Revolução Agrícola, a humanidade prosseguiu na trajetória de agressões antropogênicas cada vez mais intensas e, hoje, globalizadas. O salto qualitativo mais importante destas intervenções foi sem dúvida a Revolução Industrial no século XIX, juntamente com as Revoluções Energética e da Informática no século XX. Dois aspectos merecem destaque nessas etapas mais recentes da Transição Ecológica. Em primeiro lugar, corresponde sublinhar a velocidade 
e a magnitude das transformações. Se entre a Revolução Agrícola e a Revolução Industrial transcorreram centenas de séculos e inverteu-se a proporção entre produtos de origem natural e modificada (de 80 e 20 por cento, respectivamente, à proporção inversa), entre a Revolução Industrial e as revoluções provocadas pelo aparecimento dos combustíveis fósseis e da automatização passaram-se menos de um século, o suficiente para que se tornassem predominantes os insumos de conhecimento. Entre as múltiplas consequências destes dois processos, há que se recordar que os tempos de resposta dos sistemas naturais são exponencialmente mais lentos do que o ritmo das transformações mencionadas.

Em segundo lugar, a direção e o conteúdo das mudanças tem sido igualmente revolucionário, representadas pelas suas manifestações tecnológicas e ecológicas da Transição. As expressões tecnológicas desse "grande ciclo" que começou há nove mil anos indicam que, apesar da crescente sofisticação das sucessivas civilizações humanas, requeremos de quantidades cada vez maiores de energia e com crescentes níveis de ineficiência (i.e., de entropia). Mais preocupante ainda para as possibilidades de superação das mudanças ambientais globais de hoje e garantir a manutenção da espécie humana, é reconhecer o componente ecológico da Transição. Isto deve-se ao fato de que, em termos estritamente ecológicos, as práticas agrícola e pastoril referidas à base territorial da sociedade, ao promover a especialização da flora e da fauna, contrariaram as leis mais fundamentais de funcionamento da natureza, tais como as de diversidade, resiliência, capacidade de suporte e equilíbrio. Apesar das consequências ambientais nos dias de hoje, ninguém estaria politicamente disposto - ou suficientemente insano, conforme o caso - para sugerir que os processos iniciados pela Revolução Agrícola fossem revertidos. Como já assinalado, não se pode sequer imaginar uma sociedade civilizada se não houvesse ocorrido essa evolução na ocupação do planeta, mas é o próprio planeta que, como Gaia, assume um papel de ator e exige que a sociedade assuma plenamente a encruzilhada a que chegou. Como advertiu com muita propriedade Margaret Mead, somos forçados hoje a considerar

os modos de vida de nossos antepassados como algo ao qual jamais seremos capazes de retornar; mas podemos resgatar essa sabedoria original de um modo que nos permita compreender melhor o que está ocorrendo, quando uma geração quase inocente de um sentido de história tem que aprender a conviver com um futuro incerto, um futuro para o qual não foi educada. (MEAD, 1970, p. 70).

A evolução descrita revela-se crucial para sublinhar a característica humana das mudanças ambientais globais. Se é certo que estas não constituem novidade alguma do ponto de vista ecológico, para o planeta - sejam as referidas às mudanças climáticas, à desertificação e outras - nunca antes ocorreram em um período de tempo tão curto, provocadas, ou, no mínimo, agravadas, por ações humanas. Também é certo que os pilares humanos da sustentabilidade planetária possuem um peso muito superior ao dos ciclos naturais. Afinal, o que determina a qualidade de vida de uma população, e por conseguinte, a sua sustentabilidade, não é unicamente o seu entorno natural, mas a trama de relações que configura um determinado padrão de ocupação do território que, por sua vez, determina o modo como os seres humanos incorporam a natureza à sociedade. Fazendo uso de uma imagem sugerida inicialmente por Ottis Duncan (1961), ainda que para propósitos distintos aos da presente análise, a sustentabilidade de uma comunidade depende das inter-relações entre:

- População (tamanho, composição e dinâmica demográfica);

- $\quad$ Organização social (padrões de produção e de resolução de conflitos, e estratificação social);

- $\quad$ Entorno (ambiente natural e construído, recursos naturais e serviços ambientais);

- Tecnologia (inovação, progresso técnico, uso de energia);

- Aspirações sociais (padrões de consumo, valores, cultura).

Revista da ANPEGE. v. 6, 2010 (jan./dez.) 
A equação do POETA (cf. GUIMARÃES, 1991a) permite entender, por exemplo, por que um país como o Japão deveria ocupar o ranking dos países mais pobres do planeta sob uma perspectiva estritamente ecológica e demográfica, pois possui uma alta densidade demográfica para o tamanho de seu território e é extremamente pobre em matéria de recursos naturais e de fontes tradicionais de energia. Não obstante, o Japão ocupa uma posição de destaque na pirâmide dos países mais desenvolvidos e com maior qualidade de vida, graças, especialmente, ao seu tecido social e organização tecnológica. O padrão de consumo japonês responde e ao mesmo tempo determina a existência de padrões de produção de acordo com suas aspirações sociais, e se adapta (na verdade, supera) as limitações ambientais e territoriais do país. É a perfeita convergência entre produção e consumo que outorga sustentabilidade ao Japão. Em outras palavras, tem sido a possibilidade (exitosa) de incorporação de territórios muito apartados do Japão que confere um signo de sustentabilidade aparentemente dura a um estilo de desenvolvimento que, de outro modo, seria extremamente débil e frágil (PEARCE; ATKINSON, 1993; para uma visão crítica, ver MARTINEZ-ALLIER, 1995).

Em síntese, a evolução do padrão de ocupação do planeta, que teve lugar a partir da Revolução Agrícola, levou a uma verdadeira revolução nos padrões de produção e consumo. Esse mesmo padrão que permitiu o surgimento da civilização foi tornando os seres humanos cada vez menos sintonizados com suas necessidades biológicas e mais alienados de si mesmos e dos seus parceiros na natureza. Soma-se a isto, a necessidade de utilização de quantidades crescentes de recursos de poder para garantir a incorporação (e destruição) de ambientes extra-nacionais e, desta forma, satisfazer padrões progressivamente mais insustentáveis de consumo. Como sugerem Guimarães e Maia (1997), a sustentabilidade de um determinado território estará dada, na sua expressão ambiental, pelo nível de dependência deste em relação a ambientes extra-locais, e em termos socioambientais, pela distância entre a satisfação das necessidades básicas de seus habitantes e o consumo conspícuo de suas elites.

A partir dessa compreensão mais adequada da evolução histórica das relações entre seres humanos e natureza, não deveria surpreender a ausência de uma argumentação ecológica e ambiental no pensamento sociológico, político e econômico tradicional. Não surpreende tampouco a "disfuncionalidade" da maioria das instituições políticas contemporâneas para enfrentar adequadamente os desafios do esgotamento da transição que as mudanças ambientais revelam na atualidade. Criadas em um mundo onde predominava a abundância e a imensidão do território disponível, estas revelam-se claramente incapazes de oferecer respostas a uma crise de escassez ecológica (i.e., de recursos naturais) e ambiental (i.e. de serviços). Não surpreende, por fim, a insistência em enfoques ingênuos, parciais, dependentes de magias tecnológicas e outras para superar a crise de sustentabilidade. Enfoques estes que tem-se pautado por tratar as mudanças ambientais a partir de uma visão da organização social que, além de fragmentada e tecnocratizada, supõe uma relação de equilíbrio entre Seres Humanos e Natureza. Por isso mesmo, constituem aproximações e receitas parciais, tais como a incorporação da "variável" ambiental nas decisões econômicas, métodos de avaliação de impacto, incentivos econômicos e outros remendos de engenharia social.

A realidade parece haver superado a fantasia que encobre a progressiva alienação dos seres humanos em relação à natureza e que levou à própria alienação entre seres humanos. A crise das mudanças ambientais globais parece estar produzindo um tsunami que submerge em suas águas as "certezas" de tecnocratas economicistas e conservacionistas ambientais por igual. Antes de imaginar que serão as novas tecnologias ou a restauração pura e simples do ambiente natural que irão permitir escolher o caminho adequado ante a encruzilhada provocada pelos estertores de uma Transição Ecológica que chega ao fim, há que reconhecer, antes de tudo, que as mudanças ambientais não obedecem às leis naturais, pelo contrário, representam o produto do efeito acumulativo de ações humanas crescentemente sem sincronia com os 
ciclos vitais. Mais importante ainda é reconhecer que as mudanças ambientais globais revelam disfunções de caráter social e político (os padrões de relacionamento entre seres humanos e a forma como esse organiza a sociedade em seu conjunto), além de representarem o resultado de distorções estruturais e de falências, tanto econômicas quanto produtivas, ou seja, os padrões de consumo da sociedade e a forma como esta se organiza para satisfazê-los.

\section{MODERNIDADE, MUDANÇAS AMBIENTAIS GLOBAIS E CRISE DE CIVILIZAÇÃO}

Tem gente que quer ter um carro importado. Para mim basta um Fusca. Afinal, carros são máquinas usadas pelas pessoas para se locomover. Eu quero ter o poder de comprar um carro importado, só para ter o prazer de não comprá-lo.

Rui Lopes Viana Filho, Medalha de Ouro na 39ª Olimpíada Internacional de Matemática, 1998

Para captar em toda a sua magnitude o impacto das mudanças ambientais globais na agenda internacional, convém resgatar o contexto das mudanças na modernidade atual (GUIMARÃES, 2003). Nesse sentido, a modernidade deve ser entendida como um projeto social que busca enfrentar ou dar resposta a processos de mudança profundos. Não é por outro motivo que as sociedades se desenvolveram sob sucessivas modernidades ao longo de seus projetos civilizatórios. Entretanto, contrariamente ao que tratam de convencer-nos os curadores da "pós-modernidade", uma aproximação à complexidade e aos valores que caracterizam a sociedade atual não requer de conhecimentos e capacidade de análise sofisticados. Talvez seja esta a razão para que não tenham sido necessárias mais do que umas poucas palavras para que esse jovem matemático resumisse a crise atual e tomasse uma posição.

As relações entre modernidade e meio ambiente constituem as verdadeiras tensões provocadas pela trajetória da civilização ocidental a partir da aludida Transição Ecológica, no sentido empregado por Kuhn (1977) para designar a necessidade de conhecimento convergente para superar a razão científica e transcender paradigmas vigentes. De fato, modernidade e meio ambiente representam o resultado de uma mesma dinâmica, o progressivo protagonismo do ser humano com relação às super estruturas e, ao mesmo tempo, a progressiva importância que assume a necessidade atual de redefinir as relações entre estes e a natureza por intermédio de um novo padrão civilizatório. Ademais, a preocupação com as mudanças ambientais globais questiona tão profundamente a modernidade atual de tal forma que conduz aos fundamentos particularmente éticos (como veremos adiante) de um novo paradigma de desenvolvimento.

Se meio ambiente e modernidade puderam nutrir-se da mesma fonte civilizadora para chegar a constituir hoje os verdadeiros dilemas ou desafios do novo milênio, é precisamente o conteúdo ético desse questionamento que opera como o agente catalisador, ou amálgama, que confere sentido e direção à tensão explicitada por Khun. Assim como o socialismo representou a resistência anti-sistêmica à modernidade "industrial" hegemônica construída pela Inglaterra a meados do século XIX, a construção da agenda ambiental internacional, bem como os movimentos sociais que subjazem a esta, representa a resistência à modernidade "do consumo" que emerge cem anos mais tarde e construída agora sob a hegemonia dos Estados Unidos (TAYLOR, 1997). Ambas dinâmicas de resistência somente conseguem superar a modernidade, como paradigmas de conhecimento e de ação pública, na medida em que outorgam um caráter central às opções de valor em resposta à evolução dos processos sociais e de sua interação com o ambiente. As palavras de Rui Lopes indicam que saber precisar a verdadeira dimensão de um automóvel na sociedade (i.e., independente do status adicional por ser "importado") já constitui, em si mesmo, um ato de extrema lucidez. Exercer, entretanto, a potestade de optar por uma alternativa para satisfazer

Revista da ANPEGE. v. 6, 2010 (jan./dez.) 
suas necessidades, além do poder social (moeda de troca na modernidade do consumo), confere ao ser humano o prazer como indivíduo (medida de bem-estar).

Os comentários introduzidos até aqui, referidos à relação entre modernidade e as mudanças ambientais globais, devem ser enriquecidos pela mesma análise do significado do apêndice "global" para qualificar as mudanças ambientais e, deste modo, poder sugerir, justificadamente, que o caráter genuíno da globalização foi precisamente a transformação das mudanças ambientais em desafios globais.

Já se afirmou que a globalização, um conceito que adquiriu força nas últimas décadas do século passado, parece ter se transformado em uma forma mística (mantra) da modernidade contemporânea, $o$ capítulo de um livro sagrado (e desconhecido) sobre a sociedade secular, um capítulo que inclui quase tudo o imaginável: demografia, economia, política internacional, tecnologia, ecologia, salubridade, etc., tal como, analogamente, os verdadeiros mantras dos Vedas (livros sagrados hindus) continham orações, poesias, oráculos, músicas, coreografias, receitas, etc. De tal forma que, ao que tudo indica, a globalização tornou-se a (súmula) máxima do capitalismo atual, o capitalismo tecnológico, já não mais comercial, industrial ou financeiro (BOISIER, 1999).

Tornando as águas ainda mais turvas, a maioria dos cenários atuais enfatiza o processo de globalização sem, contudo, aportar clareza ou elucidar interrogantes (Guimarães, 2001a). Na verdade, a globalização inclui fenômenos diferenciados, conduzindo frequentemente à interpretações contraditórias. Alguns autores definem o processo em termos exclusivamente econômicos (crescente homogeneização e internacionalização de padrões de produção e consumo), financeiros (a magnitude e interdependência de fluxos internacionais de capital), ou comerciais (aumento da exposição externa e abertura das economias nacionais). Outros preferem enfatizar o caráter da globalização em suas dimensões políticas (predomínio e difusão das democracias liberais e das liberdades civis, como também novas formas de participação social e responsabilidade pública - "accountability") e institucionais (predomínio de forças de mercado, convergência de mecanismos e instrumentos de regulação, flexibilidade de mercados laborais, etc.). Por outro lado, ainda outros privilegiam a velocidade das mudanças tecnológicas (seus impactos no aparato produtivo, em mercados de trabalho e nas estruturas e relações de poder) e a revolução impressionante dos meios de comunicação de massas ("massificação" do acesso, transmissão e disseminação de informações, maiores perspectivas para a descentralização e a possível erosão de identidades culturais).

Fazendo uso de uma aproximação distinta para analisar fenômenos claramente multi-facéticos - enfocando a globalização como um processo mais que como um conjunto de vetores específicos - alguns estudiosos preferem analisar o processo de mundialização sob o prisma das relações internacionais e do aparecimento de novas alianças e blocos econômicos, comerciais e políticos. Não são poucos, porém, entre os quais se incluem os autores deste trabalho, que consideram mais adequado desvelar globalização a partir de uma perspectiva de sustentabilidade. Estes questionam, por exemplo, a racionalidade econômica globalizadora vis-à-vis a lógica e o tempo dos processos naturais. Em outras palavras, os fluxos de capital podem ter se tornado "globais", o mesmo não tendo acontecido em relação ao trabalho ou aos recursos naturais.

Questiona-se também seriamente as possibilidades de um processo de globalização fundado em um modelo de crescimento econômico ascendente e ilimitado, particularmente, devido à realidade de esgotamento de muitos recursos naturais (por exemplo, fauna, flora e fontes não renováveis de energia) como também de deterioração de processos naturais que são cruciais para a viabilidade da vida no planeta (camada de ozônio, clima, etc.). Como sugere Kenneth Boulding, um dos principais pioneiros da sustentabilidade, com muito sarcasmo, qualquer pessoa que acredita que é possível um crescimento 
econômico exponencial em um mundo finito ou é louco... ou economista. Finalmente, os que subscrevem a estes e a outros questionamentos apontam à crescente insustentabilidade social do atual estilo, uma realidade de globalização em meio à desigualdade, exclusão, e que certamente precede, mas que foi sem dúvida exacerbada pelo próprio processo de globalização (Sen, 1989, Stiglitz, 2002, Guimarães, 2007).

Efetivamente, os desafios ambientais revelam o aspecto mais genuíno e central do conceito de "globalização" (GUIMARÃES, 2001b). Por um lado, muitos problemas ambientais somente assumem o caráter de preocupação internacional quando manifestam os seus impactos globais. São processos locais, como por exemplo, a queima de combustíveis fósseis, que produzem dinâmicas globais como o efeito estufa e as mudanças climáticas que afetam o mundo inteiro, incluindo a imensa maioria que, mesmo sem contribuir para o aquecimento global, sofrem os impactos mais significativos, os países insulares. Existem a cada dia mais evidências científicas de que o aumento das temperaturas médias do mar, como resultado das mudanças climáticas, está provocando a extinção dos arrecifes de coral. Até há pouco, a degradação dos arrecifes era o resultado da sua extração, do turismo predatório, da poluição marinha, da destruição dos manguezais, etc. - todos processos locais - enquanto que a causa predominante da degradação é o processo global de aquecimento do planeta.

Ainda mais importante é a constatação de que, se nenhum país está imune às consequências das mudanças ambientais globais que perturbam ao limite os ciclos vitais da natureza, as soluções à crise de sustentabilidade global dependem da ação coordenada de todos os países. Não foi por outro motivo que emergiu da Rio-92 a idéia-força de "pensar globalmente, atuar localmente". De fato, os desafios globais dependem cada vez mais das sustentabilidades locais, como reconhece um dos baluartes do estilo de desenvolvimento ainda dominante, o Banco Mundial (2000).

Neste sentido, pode-se aprofundar a perspectiva socioambiental do questionamento, lembrando que o caráter da globalização, ou pelo menos da ideologia neoconservadora que legitima a modernidade ainda hegemônica, parece admitir apenas duas alternativas para os países emergentes: ou se integram completamente ao mercado mundial (ainda que de forma subordinada e dependente), ou não haverá nada mais para esses países que a realidade de atraso mascarada pela ilusão de desenvolvimento autônomo. A posição defendida aqui supõe, entretanto, que o cerne dos desafios atuais não é a tendência inevitável de inserção em um mundo crescentemente globalizado, mas sim o modo de inserção que convém às economias emergentes, se os padrões atuais de inserção permitem a esses países manter o controle nacional do crescimento, e quais alternativas garantem a coesão social, a identidade cultural e a integridade ambiental. Tem razão Octávio Paz (1990, p.57) quando nos ensina que a verdadeira liberdade e autonomia dos povos define-se por sua capacidade de optar por distintas alternativas: "a liberdade não é uma filosofia, sequer uma idéia: é um movimento da consciência que nos leva, em certos momentos, a pronunciar dois monossílabos: Sim ou Não.”. Como Alfredo Calcagno, pai e filho, indicam em brilhante livro que desmistifica o neoliberalismo:

Nos dizem que devemos subir, a qualquer custo, no trem da modernidade (como se houvesse apenas um), embora não saibamos aonde nos levará, se poderemos subir a bordo como passageiros de primeira classe ou pessoal de serviço que é mandado de volta à origem terminada a viagem, ou se chegaremos ao destino final como trabalhadores imigrantes. Em resumo, somos aconselhados, como países soberanos, a adotar um comportamento que nenhum liberal (de fato, nem mesmo uma pessoa sã) tomaria em uma estação de trem.

(CALCAGNO e CALCAGNO, 1995, p. 265).

Em resumo, a crise dos atuais paradigmas de desenvolvimento provocada pelas mudanças ambientais globais diz respeito ao esgotamento de um estilo de desenvolvimento ecologicamente depredador,

Revista da ANPEGE. v. 6, 2010 (jan./dez.) 
socialmente perverso, politicamente injusto, culturalmente alienado e eticamente repulsivo. O que está em jogo é precisamente a superação dos paradigmas de modernidade que tem definido a orientação do processo de desenvolvimento e a sua substituição por um paradigma de desenvolvimento sustentável que coloque os seres humanos no centro do processo de desenvolvimento, que considere o crescimento econômico como um meio e não como um fim em si mesmo, que proteja as oportunidades de vida para as gerações atuais e futuras, que respeite a integridade dos sistemas de suporte à vida no planeta e que, em última instância, garanta uma qualidade de vida que reflita a dignidade necessária à humanidade.

\section{ÉTICA E POLÍTICA, OS PRINCIPAIS DESAFIOS PARA ENFRENTAR A CRISE DE SUSTENTABILIDADE}

Um dos mitos afortunadamente desfeitos pela comunidade científica é a de que todas as mudanças ambientais globais, em especial as mudanças climáticas, respondiam ao funcionamento "natural" dos ciclos planetários. Hoje já não se discute que a grande maioria dessas mudanças foi provocada pela ação humana. Entretanto, ainda resta corrigir uma concepção inadequada. É tido como correto afirmar que grande parte das dificuldades para enfrentar adequadamente a crise seja provocada por instituições, cujo desenho e regime foram criados para um mundo virtual e, em alguns casos, literalmente em extinção. No entanto, a verdade é que, ainda assim, são as ações humanas, individuais e coletivas, que levaram à insustentabilidade atual, seja diretamente, por decisões de produção e consumo, seja indiretamente, através das instituições igualmente fruto de ações e decisões humanas, individuais e coletivas. Em resumo, deve-se assumir que as mudanças ambientais globais não são impulsionadas por instituições, mas por seres humanos.

Por conseguinte, o que o mundo enfrenta hoje não é um déficit de ciência, nem mesmo um déficit institucional. Ainda que persista muita incerteza científica, não mais sobre as causas, mas sobre as consequências das mudanças globais, e ainda que persistam as dificuldades institucionais, o déficit atual é claramente político, de implementação de decisões já adotadas reiteradamente. Como afirmou a Embaixadora de Granada, Dessima Williams (2009), que Preside a Aliança dos Pequenos Estados Insulares, em um encontro científico internacional, recentemente: "Viemos aqui como embaixadores do planeta para alertar as sociedades ocidentais de que precisamos de ações, AGORA."

É com este enfoque que se deve notar que o maior desafio da atualidade resulta ser menos de caráter institucional ou de governança. Tal como foi sublinhado no início desta análise, o desafio é político e diz respeito a ações concretas de atores específicos e claramente identificáveis. Justifica-se, portanto, fazer eco às análises agudas de um dos maiores cientistas políticos do século XX, Aaron Wildavsky (1979), que teve a felicidade de indicar, já no título do que é hoje um clássico da análise de políticas públicas, que devemos "transmitir a verdade ao poder". Por desgraça, a realidade atual de poder no mundo parece estar respondendo negativamente aos alertas de Wildavsky. Em um discurso recente dos maiores cientistas políticos, discorrendo justamente sobre os desafios ambientais, Immanuel Wallerstein (2002) recordou os ensinamentos de Wildavsky, mas chega à triste conclusão ao perguntar "Está o poder disposto a escutar?"

Para aprofundar melhor o que se acaba de sugerir, nada mais adequado do que utilizar a análise de um dos trabalhos mais aclamados na atualidade, ganhador, entre muitos outros reconhecimentos internacionais, do Prêmio Pulitzer. De acordo com a monumental obra de Jared Diamond (2006), o estudo das sociedades que fracassaram no passado, algumas das quais chegaram à extinção, comparando-as com as sociedades atuais, revela que, entre os diversos fatores que levaram ao seu colapso, destacamse, principalmente, a incapacidade de: (1) antecipar, (2) perceber, (3) comunicar e (4) atuar para, frente 
a tendências negativas, corrigir o rumo presente e superar as ameaças que colocam em risco a própria sobrevivência da comunidade.

Não cabe dúvida que a humanidade respondeu adequadamente aos três primeiros desafios enunciados por Diamond para enfrentar uma das ameaças mais agudas das mudanças ambientais globais: a representada pelo aquecimento das temperaturas médias da atmosfera terrestre. A criação do IPCC, sigla em inglês do Painel Intergovernamental de Mudanças Climáticas, teve por objetivo, precisamente, dar resposta aos interesses políticos de atores poderosos que insistiam em desqualificar os alertas sobre o aquecimento global. Criado em 1988 com a participação de delegados científicos de mais de 130 países, em 2007 emitiu o primeiro relatório que comprovava cientificamente a ação do homem como a principal causa não-natural das mudanças no clima. Em outras palavras, a partir de então, já não se pode afirmar que o mundo não soube antecipar a ameaça do efeito estufa.

Por outro lado, além do fato de que os relatórios do IPCC são objeto de revisão e aprovação por expertos e delegados oficiais de governos (representando, portanto, além da Ciência, também o Poder), existem inúmeras organizações internacionais dedicadas ao estudo e divulgação de iniciativas científicas em matéria de mudanças ambientais globais. Entre estas o IHDP - Programa Internacional sobre as Dimensões Humanas das Mudanças Ambientais Globais, o ESSP - Parceria para a Ciência da Terra, o IGBP - Programa Internacional Biosfera - Geosfera, DIVERSITAS, programa internacional integrado de ciência da biodiversidade, o WGRP - Programa Mundial de Pesquisa sobre Água, dentre muitas outras iniciativas nacionais e internacionais. É igualmente equivocado, assim sendo, não reconhecer que o mundo já deu mostras suficientes de ter percebido claramente as ameaças ambientais.

Finalmente, o tema de mudanças ambientais globais, algo ao restrito círculo de ambientalistas e cientistas, é hoje parte integrante da agenda internacional e das preocupações cotidianas dos indivíduos. $\mathrm{O}$ aquecimento global já foi tema central de diversas reuniões de cúpula mundial, do próprio Conselho de Segurança da ONU e de reuniões dos chamados G-8 e G-20, que reúnem os países mais ricos e mais poderosos do planeta. Quando um dos autores deste trabalho teve o privilégio de atuar como Coordenador Técnico da preparação do documento que o Brasil apresentou na Rio-92, temas como biodiversidade, efeito estufa, camada de ozônio (ou ozono) e outros eram tão desconhecidos que, em qualquer reunião, havia que dedicar a parte introdutória apenas para explicar o significado de cada um. Hoje, menos de duas décadas mais tarde, são temas que fazem parte do cotidiano, objetos de matérias e reportagens especiais em todos os meios de comunicação e é muito difícil encontrar alguém que não tenha opinião sobre cada uma das mudanças ambientais globais, independente de sua ocupação, posição social ou interesse como cidadão. Em resumo, tampouco a comunidade científica e política fracassou em comunicar à humanidade do perigo que se avizinha cada vez mais próximo.

A questão hoje é tentar reverter o fragoroso fracasso de atores com poder de decisão para atuar no sentido de remover as causas de ameaças cientificamente comprovadas e cujas consequências desastrosas também são cientificamente conhecidas. Além disso, até muito pouco tempo atrás, a Ciência preocupavase em simplesmente comprovar, com a cautela e conservadorismo característicos dessa comunidade, as consequências das mudanças ambientais globais. Hoje, a cada novo estudo, a cada novo relatório, a comunidade científica é obrigada a reconhecer que suas previsões não eram o que indicavam. Os cenários sobre o futuro são, na verdade, sucessivamente muito piores, seja na magnitude das mudanças, seja no horizonte de tempo para que a humanidade comece a sentir os seus efeitos. Diante deste contexto, podese argumentar que não falta conhecimento ou vontade política para atuar, nem mesmo a cegueira típica de atores que só se guiam pelo curto prazo, como os que atuam no marco dos mercados econômicos e financeiros em geral.

Revista da ANPEGE. v. 6, 2010 (jan./dez.) 
A crise financeira que eclodiu em meados de 2008 deveria ser suficiente para calar as vozes que ainda insistem em justificar a inação, pese a gravidade da situação, aludindo à interesses de ordem econômica que "impedem" a adoção das medidas necessárias para evitar o colapso. Neste caso, não se pode sequer afirmar que a Ciência não soube antecipar, perceber e comunicar a gravidade da situação. Economistas do porte de Nouriel Roubiny, da Universidade de Nova York, Robert Schiller, da Universidade de Yale, e Paul Krugman, da Universidade de Princeton e ganhador do Prêmio Nobel de Economia de 2008 (para mencionar apenas um grupo na multidão) vinham fazendo sucessivos alertas sobre o iceberg aproximandose do Titanic especulativo e depredador de Wall Street há mais de dois anos antes da crise. Na verdade, comprovando o acerto das análises de Jared Diamond, a crise financeira demonstrou claramente que, apesar da cegueira inicial às advertências (e politicamente interessada), surgiram, imediatamente após a eclosão da crise, mais do que suficientes atores políticos decididos a atuar. E a atuar de um modo que não se tem notícia na história recente.

A poucas semanas do início da crise, o Poder finalmente se dispôs a "escutar" o que dizia a Ciência (econômica). Está claro que isto não aconteceu devido à força dos argumentos ou fatos irrefutáveis, mas pela força dos acontecimentos (sucessivos "colapsos"). Nesse período o mundo descobriu que a ausência de recursos para resolver os problemas da pobreza, garantir o cumprimento dos Objetivos contidos na Declaração do Milênio ou adotar as medidas mais urgentes para reverter o aquecimento global, repentinamente, surgiram "do nada" para superar a crise financeira. Em que pese a discrepância entre as estimativas dos recursos financeiros aportados pelos governos para resolver a crise - entre oito e onze trilhões de dólares norte-americanos - estes representaram quase duas vezes e meia o custo total destinado à reconstrução da Europa após a Segunda Guerra mundial.

Para captar melhor a força dessa "vontade política" para atuar, é suficiente sublinhar que o volume de recursos passados ao setor financeiro equivale a mais de 130 vezes o volume total de Ajuda Oficial ao Desenvolvimento (aproximadamente US\$80 bilhões em dezembro de 2008), ou 55 vezes superior ao Investimento Estrangeiro Direto Líquido (aproximadamente US\$200 bilhões no período 2000-2007). Se, ao invés de entregar esses recursos às instituições financeiras colapsadas por ações de suas responsabilidades, os recursos tivessem sido destinados diretamente às pessoas endividadas, o resultado é realmente impressionante, e a crise teria, certamente, outro desfecho. Ainda supondo o total das populações da América do Norte, Europa Ocidental e Japão (as regiões que geraram e mais sofreram os efeitos do "aquecimento global" da especulação financeira), isto equivaleria a entregar US\$50 mil dólares em cada domicílio, o que constitui um cálculo claramente subestimado, pois a população afetada foi muito inferior. Não há dúvida que o desfecho teria sido outro e as repercussões na economia "real" radicalmente distintas.

Seja como for, posto que a análise da Economia Política do poder mundial na atualidade escapa do escopo desta análise, o importante é ressaltar que a debacle financeira, ao comprovar o acerto de Jared Diamond, coloca a descoberto que a crise provocada pelas mudanças ambientais parece obedecer à mesma trajetória das sociedades que colapsaram no passado. Afortunadamente, existem suficientes exemplos exitosos da relação entre Ciência e Poder.

O declínio da indústria de geração de energia nuclear nos anos 70 e 80 constitui uma ilustração clara dos resultados da aliança entre cientistas e movimentos sociais, que não pode ser explicado aludindo às instituições ou à governança. Foi a sociedade em seu conjunto que, em certa medida, ao levar o tema metaforicamente "para a rua", terminou prevalecendo, apesar das barreiras institucionais e de governança. Talvez a ilustração mais exemplar (e exitosa) dessa dinâmica tenha sido a política anti-fumo. Neste caso, novamente, a aliança entre a Ciência (médica) e a Sociedade foi forte o suficiente para vencer os 
interesses de atores entre os mais poderosos economicamente (a indústria do tabaco) e obrigou o Poder a atuar para coibir o cigarro.

O que fica patente com a análise feita é que os desafios mencionados, exitosos ou não, revelam o caráter central de uma discussão ética e política das mudanças ambientais globais. Como resumiu muito apropriadamente Klaus Schwab, fundador do Fórum Econômico de Davos, a poucas semanas da eclosão da crise financeira:

Apesar de primordiais para o futuro da economia global, a regulamentação não é o suficiente [...] a gestão de uma empresa deve ser direcionada a todos os agentes ligados a ela. Os princípios da teoria preconizam uma administração para além dos interesses exclusivos dos acionistas, devendo ser fiduciário de todas as partes interessadas para garantir a prosperidade do negócio [...] Precisamos de uma filosofia de administração de empresas baseada na ética profissional e não na maximização de lucros. (SCHWAB, 2009, p. 6, ênfase adicionada).

O que foi comentado permite introduzir uma advertência necessária que, em certa medida, resume as lições do que foi analisado. Está mais do que claro (cientificamente) que o "iceberg" das consequências das mudanças ambientais já pode ser visto na linha do horizonte. Também é científica e socialmente sabida a dificuldade de manobra para mudar o curso de um "Titanic" como a sociedade global do dias atuais. Isto importa em, ao menos, duas advertências em forma de sugestão para futuras pesquisas.

Em primeiro lugar, ainda que a comunidade científica deva manter as linhas de pesquisa tradicionais em matéria de mudanças ambientais globais, faz-se necessário outorgar prioridade aos temas transversais, em especial àqueles relacionados com aspectos éticos, distributivos das mudanças ambientais e as formas de relacionamento entre a comunidade científica, a polis e a sociedade civil. Afinal, a comunidade científica, tanto das ciências naturais como, em particular, das ciências sociais, demonstraram ser os melhores e mais acurados binóculos de que dispõe a sociedade para vasculhar o horizonte, e foram elas que detectaram, inicialmente, a presença do iceberg e, mais recentemente, a velocidade da sua aproximação.

Por outro lado, devem-se criar novas formas de atuação. Sabe-se que a tripulação do Titanic antecipou, previu e comunicou com suficiente tempo a eminência do choque. Teria sido desastroso, nesse momento, iniciar um debate científico sobre a governança do Titanic, ou ainda sobre as instituições da indústria naval. Como um exemplo típico do que poderíamos classificar como "a síndrome de Jared Diamond", o que faltou foi, aos que detinham o poder de decisão, atuar a tempo para mudar o curso do Titanic, que teria evitado sem maiores problemas o choque e colapso final. E as razões para não atuar se assemelham muito às dos donos do poder de hoje. Antes de tudo, em acreditar que o Titanic era "inafundável". Segundo, em recusar-se a tomar uma medida preventiva sob a hipótese de que, se estivessem errados, os resultados seriam desastrosos, como de fato o foram.

Infelizmente, os capitães do Titanic atual não podem sequer se esconder detrás dessa crença, pois já vivemos numa era que consagra o princípio da precaução, cuja base principal ensina que em situações de incerteza científica (o que já não é mais o caso), esta incerteza não justifica a inação. Isto porque caso a hipótese negativa seja confirmada, as consequências podem ser nefastas, e, provavelmente, será tarde demais para evitar o colapso. Contrariamente ao que indicam os filmes de ficção, na crise atual, qualquer semelhança entre a metáfora feita aqui e a realidade não será mera coincidência.

Em resumo, já não se pode reduzir a crise do desenvolvimento provocada pelas mudanças ambientais globais a uma questão de manter limpo o ar que respiramos, a água que bebemos, o solo que produz nossos alimentos. A constatação de que, sim, somos todos passageiros de uma mesma "nave Terra" e de que, sim, sofremos, todos, os efeitos do mau estado em que se encontram os sistemas vitais do planeta, 
não pode dar lugar a soluções simplistas, mal disfarçando o substrato político dos interesses de cada navegante. Quando a todos os países, ricos e pobres, são lembradas as suas responsabilidades comuns em relação às gerações atuais e futuras, haveria que agregar também que existe uma realidade de dominação que matiza tanto as relações diacrônicas, entre gerações, como as de caráter sincrônico, entre os seres humanos e a natureza. Antes de procurar argumentos técnicos para as decisões necessárias para superar a crise socioambiental, há que se buscar construir as alianças políticas adequadas, cuja "racionalidade" é definida de acordo com os interesses dos atores envolvidos. Já não se pode mais repetir o chavão de que "falta vontade política". Na verdade, o que existe é o "excesso de vontade política" para que não sejam adotadas as decisões que o momento exige.

O tempo da retórica das elites conservadoras se esgota mais rapidamente do que o degelo dos glaciares. É certo que as leis da sociedade tomam tempo para amadurecer e dependem fundamentalmente da vontade humana para mudar, mas as leis de funcionamento dos sistemas naturais obedecem seu próprio curso e não esperam pela ação do ser humano para tornar visíveis os resultados da sua degradação, como o demonstram com dramaticidade os efeitos sociais e econômicos das mudanças ambientais globais. $\mathrm{O}$ estudo de civilizações passadas oferece suficientes ilustrações de sociedades que, apesar de sua fortaleza econômica, social, tecnológica e até mesmo militar, desapareceram por sua incapacidade de reconhecer os limites socioambientais do seu padrão de desenvolvimento. Analogamente, nenhum ser humano deveria estar condenado a uma vida breve ou miserável apenas porque nasceu "na classe incorreta, no país errado ou com o sexo equivocado" (PNUD, 1994).

Para que exista desenvolvimento faz-se necessário, mais do que a acumulação pura e simples da riqueza, mudanças na qualidade de vida e na felicidade das pessoas. Mudanças que transcendem as expressões mercantis das transações no mercado, e incluem dimensões sociais, culturais e éticas. De fato, uma geração na qual predomine a pobreza, a exclusão e a degradação do ambiente, além de aprofundar o uso predatório dos recursos, a alienação e perda de identidade dos seres humanos, representa a garantia mais segura de que não haverá geração futura. Pelo menos não uma geração na qual valha a pena sentir-se membro.

Tinha razão Dwight Eisenhower ao despedir-se da presidência dos Estados Unidos, quando denunciou os perigos da conformação de um complexo industrial-militar, em circunstâncias em que os povos já estavam cansados da guerra e da consequente militarização da sociedade. Os desejos de paz se faziam sentir com tal intensidade que, dizia Eisenhower, "um desses dias os governos deveriam sair do caminho e deixar que eles [os povos] a desfrutem" (LYON, 1974, p. 845). É chegado o momento em que as instituições sociais e políticas saiam do caminho para não impedir a transição a um futuro sustentável.

Em poucas palavras, é chegada a hora para que as instituições modernas pavimentem o caminho de forma que as nossas sociedades aprendam a fazer frente, de modo sustentável, à má distribuição dos recursos e à vulnerabilidade dos sistemas naturais. Critérios tecnocráticos de eficiência econômica e de inovação, orientados exclusivamente pelas forças de mercado não conduzem à redução das desigualdades e tampouco ao uso racional dos recursos naturais. A experiência histórica demonstra que a mobilização intensiva de fatores produtivos leva ao uso predatório dos serviços ambientais e tendem a reproduzir as condições sociais pré-existentes. Mais cedo do que tarde, todos teremos que pagar o preço da irresponsabilidade ambiental e social. O recrudescimento da violência e do terrorismo representa nada mais do que a ponta visível de um iceberg esperando por provocar o naufrágio da globalização da insustentabilidade.

Impõe-se destacar ainda a realidade das relações entre seres humanos e a natureza, tal como estas se manifestam na modernidade atual. Vem de imediato à mente as palavras de Clive Lewis quando afirma que "o que nós chamamos de poder do Homem sobre a Natureza é de fato o poder de alguns homens 
sobre outros homens, usando a natureza como seu instrumento" (LEWIS, 1947, p. 69). Sendo assim, as possíveis soluções às mudanças ambientais globais via desenvolvimento sustentável terão que ser encontradas no próprio sistema social, e não em alguma mágica tecnológica ou de mercado. Nunca será demais recordar as palavras do documento que o Brasil levou à Conferência do Rio em 1992: "em situações de extrema pobreza, o indivíduo marginalizado da sociedade e da economia nacional não tem nenhum compromisso para evitar a degradação ambiental, uma vez que a sociedade não impede sua própria degradação como pessoa" (GUIMARÃES, 1991b, p. 24). Da mesma forma, se projetamos no longo prazo as realidades de poder entre os seres humanos, e suas implicações produzidas no padrão histórico de incorporação da natureza, a situação atual revela-se ainda mais delicada. Tal como foi mencionado, as relações de poder são sincrônicas, mas revelam também uma assimetria diacrônica de poder, entre as sucessivas gerações. Dito de outro modo, cada geração exerce poder (a forma como usa a natureza) sobre as gerações seguintes, enquanto estas, ao modificar o patrimônio natural herdado, resistem e tentam limitar o poder de seus antepassados. Este processo, repetido indefinidamente, antes de alcançar mais poder sobre o mundo natural, todo o contrário, termina por produzir maior precariedade na sociedade. Por definição, quanto mais posterior uma geração, mais esta viverá em um tempo cada vez mais próximo da extinção das espécies (ao aproximar-se do infinito), e menor será o seu poder sobre a natureza, ou seja, a sua capacidade de exercer poder sobre outros seres humanos.

Como conclui de maneira brilhante Clive Lewis (em uma época em que a sustentabilidade ainda não estava na moda), "a natureza humana será a última parte da Natureza a render-se ao homem [...] e os submetidos ao seu poder já não serão homens; serão artefatos. A última conquista do Homem será de fato a abolição do Homem" (LEWIS, 1947, pp. 72-77).

Tem razão Jared Diamond ao reproduzir a pergunta que lhe fez um aluno: "O que disse o último Pascuense quando cortou a última árvore existente na ilha, enquanto o fazia?” (DIAMOND, 2006, p.114). Por desgraça, a globalização, que tantos efeitos benéficos tem produzido, nos tornou, a todos, habitantes de uma "Ilha de Páscoa" global, que se confunde com a própria Terra. A diferença mais marcante entre a sociedade atual e as civilizações do passado é justamente esta. Se e quando vier a ocorrer efetivamente um colapso, pela primeira vez na história, será toda a sociedade mundial, globalizada, que sofrerá os efeitos e, eventualmente, ver desaparecer suas formas de vida. Diante desta realidade, é melhor ser otimista e acreditar na capacidade humana de reinventar-se a si mesma e seguir os ensinamentos de Dennis Gabor (1964), ganhador do Prêmio Nobel de Física em 1970, ao sugerir que "o futuro não pode ser previsto, mas futuros podem ser inventados. Foi a capacidade do homem de inventar que fez a sociedade ser o que é." (1964, p.161).

Não precisamos de mais ciência a respeito das mudanças ambientais globais para tomar decisões. $\mathrm{Na}$ verdade, estas já foram enunciadas em suficientemente número de vezes, mas não logram sair do papel ou do campo das intenções ou da retórica. Um modo de evitar o colapso é seguir o exemplo do que ocorreu nas décadas de 1970, 1980 e 1990, especialmente a partir da Conferência de Estocolmo em 1972, pois foi a sociedade que colocou o tema ambiental na agenda das preocupações internacionais, fundado precisamente nas pesquisas da comunidade científica. Infelizmente, o ego da Ciência a fez dar as costas para a sociedade. Os cientistas, naturais e sociais, que pesquisam as mudanças ambientais globais terão que deixar as suas Torres de Marfim e, emulando o exemplo da comunidade médica em relação ao fumo, engajar-se no debate com tomadores de decisão e movimentos sociais. Como foi sugerido acima, um dos pontos altos do século passado foi quando a comunidade científica de saúde e a sociedade deram as mãos numa causa eticamente correta sob todos os aspectos. Como sugeriu o Presidente Eisenhower

Revista da ANPEGE. v. 6, 2010 (jan./dez.) 
em seu discurso de despedida, em situações como essa, os "líderes" terminam sendo forçados a aceitar a liderança efetiva da sociedade.

As futuras gerações não nos perdoarão se atuarmos como a orquestra do Titanic antes dos momentos finais do colapso. Já não é hora de debater a ciência, a governança, as instituições ou os atores da mudança: é hora de atuar.

\section{REFERÊNCIAS BIBLIOGRÁFICAS}

BANCO MUNDIAL. Informe sobre el Desarrollo Mundial 2000/2001: Lucha contra la Pobreza. Banco Mundial: Wasington D.C., 2000.

BENETT, J. W. The Ecological Transition: Cultural Anthropology and Human Adaptation. Nova York: Pergamon Press, 1976.

BOISIER, S. Deshojando Margaritas: Me Quiere Mucho, Poquito, Nada... O la Importancia Potencial de las Bioregiones en el Crecimiento y Desarrollo Territorial en la Globalización del Tercer Milenio. [S.I.]: Comitê Técnico Interagencial do Fórum de Ministros do Meio Ambiente da América Latina e do Caribe, 1999.

CAlCAGNO, A. E.; CAlCAGNO, A. F. El Universo Neoliberal: Recuento de sus Lugares Comunes. Buenos Aires: Alianza Editorial, 1995.

DIAMOND, J. Colapso: Como as Sociedades Escolhem o Fracasso ou o Sucesso. Rio de Janeiro: Editora Record, 2006.

DUNCAN, O. D. From Social System to Ecosystem. Sociological Inquiry, Chicago, v. 31, p. 140-149, Inverno 1961.

GABOR, D. Inventing the Future. Londres: Pelican Books, 1964.

GUIMARÃES, R. Globalização, Desigualdade e Pobreza: A Insustentabilidade Socioambiental do "Livre-Comércio" Desigualdade \& Diversidade. Revista de Ciências Sociais da PUC-RJ, Rio de Janeiro, v. 2, p. 109-103, janeirojulho 2008.

GUIMARÃES, R. A ética da sustentabilidade e a formulação de políticas de desenvolvimento. In: VIANA, G. et al. (Org.) O desafio da sustentabilidade. São Paulo: Fundação Perseu Abramo, 2001a. p. 43-71.

GUIMARÃES, R. Fundamentos Territoriales y Biorregionales de la Planificación, Serie Medio Ambiente y Desarrollo, Santiago de Chile, v. 39, julho 2001b.

GUIMARÃES, R. ¿El Leviatán en Extinción? Notas sobre la Reforma del Estado en América Latina. Situación: Revista de Coyuntura Económica, Lima, v. 9, p. 115-143, novembro 1996.

GUimarães, R. The Ecopolitics of Development in the Third World: Politics and Environment in Brazil, Boulder: Lynne Rienner Publishers, 1991a.

GUIMARÃES, R. O Desafio do Desenvolvimento Sustentável: O Relatório do Brasil para a Conferência das Nações Unidas sobre Meio Ambiente e Desenvolvimento. Brasília: Secretaria de Imprensa da Presidência da República, 1991b. p. 13-24.

GUIMARÃES, R.; MAIA, K. Padrões de Produção e Padrões de Consumo: Dimensões e Critérios de Formulação de Políticas Públicas para o Desenvolvimento Sustentável. In: LEROY, J., MAIA, K. e GUIMARAES, R. Brasil Século XXI: Os Caminhos da Sustentabilidade Cinco Anos Depois da Rio-92. Rio de Janeiro: FASE, 1997. p. 385-397.

KUHN, T. The Essential Tension: Selected Studies in Scientific Tradition and Change. Chicago: The University of Chicago Press, 1977. 
LEWIS, C. The Abolition of Man: How Education Develops Man's Sense of Morality. Nova York: Macmillan Publishing Company, 1947.

LYON, P. Eisenhower: Portrait of the Hero. Boston: Little, Brown \& Co., 1974.

MARTINEZ-ALLIER, J. The Environment as a Luxury Good or Too Poor to Be Green?. Ecological Economics, Amsterdam, v. 13, 1995.

MEAD, M. Culture and Commitment. Nova York: Doubleday, 1970.

PAZ, O. La Otra Voz. Barcelona: Seix Barral, 1990.

PNUD. Informe sobre el Desarrollo Humano. México: Fondo de Cultura Económica, 1994.

SEN, A. Sobre Ética y Economía. México: Alianza Editorial, 1989.

STIGLITZ, J. A Globalização e os seus Malefícios: A Promessa Não Cumprida. São Paulo: Editora Futura, 2002.

SCHWAB, K. Época de Nova Ética. Jornal o Globo, Rio de Janeiro, 7 de novembro de 2008, p. 6.

TAYLOR, P. Modernities and Movements: Antisytemic Reactions to World Hegemony. REVIEW: A Journal of the Fernand Braudel Center, Binghamton, v. 1, p. 1-17, Inverno 1997.

WALLERSTEIN, I. Ecology and Capitalist Costs of Production: No Exit. Keynote address at the American Sociological Association, Santa Cruz, University of California, April 3-7, reproduzido em Sistema Mundo y Mundo Sistémico, Cidade do Panama, Universidad de Panamá, Instituto de Estudios Nacionales, pp. 115-127. 2002.

WILDAVSKY, A. Speaking Truth to Power: The Art and Craft of Policy Analysis. Nova York: Little, Brown and Co, 1979.

WILLIAMS, D. Statement at the Plenary Session on Social Equity, Cohesion and Sustainable Adaptation, 7 th. International Conference on the Human Dimensions of Global Environmental Change, Bonn, 26 a 30 de abril, doc.

Recebido em abril de 2010

Aceito em dezembro de 2010

Revista da ANPEGE. v. 6, 2010 (jan./dez.) 